\title{
PINNED - FIXED BEAM - COLUMN RESISTANCE VERIFICATION ACCORDING TO EUROPEAN STANDARDS
}

\author{
Jozef PROKOP ${ }^{1}$, Josef VIČAN ${ }^{1, *}$ \\ ${ }^{1}$ Department of Structures and Bridges, Faculty of Civil Engineering, University of Žilina, Univerzitná \\ 8215/1, 01026 Žilina, Slovakia. \\ "corresponding author: josef.vican@fstav.uniza.sk.
}

\begin{abstract}
Verification of beam-column resistance can be accomplished according to design approaches given in EN 1993-1-1 [1]. These approaches are derived from verification of single span beam with pinned end conditions subjected to compression and bending moments. In the case of different end conditions, the application of those approaches is not so accurate and more difficult. Therefore, the comparison of verification according to above standard EN 1993-1-1 [1] as well as EN 1999-1-1 [2] to results of experimental analyses of beam-columns having pinned-fixed end conditions subjected to an eccentric compressive force simulating the behaviour of columns integrated into frames is presented in this paper.
\end{abstract}

\section{Keywords:}

Beam-columns; Flexural buckling; Imperfections;

Beam-column resistance; Second-order theory.

\section{Introduction}

When designing steel structures, slender members are often used because of economic and aesthetic reasons. Therefore, member resistances against compression are many times smaller than their cross-sectional ones. However, in design practice, members are hardly ever subjected only to axial force or only to bending moment in one of the main cross-sectional planes. Members subjected to combined stresses exhibit complex behaviour, which is more difficult to determine, but is necessary to include it into design calculation. The geometrical and material imperfections are an additional phenomenon, which has significant impact to resistance of beam-column. The effect of imperfections and first-order bending moment are deflections generating concurrently second-order bending moment due to action of axial force. If the more accurate analysis is not used and imperfections are not taken into account in the numerical models, those effects must be implemented in the stability verification of members that should be accomplished according to simplified approaches given in standards [1, 2].

\section{Experimental analysis}

The actual member resistances of beam-columns subjected to end bending moments induced by eccentric axial forces at the top sides of the members were investigated by means of experimental analyses. Every tested member was fixed at the bottom and pinned at top side in both main planes of cross-section to simulate the behaviour of beam-column in a frame structure. For experimental investigation, the hot-rolled section of IPE 120 was chosen belonging to the first class from the viewpoint of cross-sectional classification. The specimen total length was $1400 \mathrm{~mm}$, so that the appropriate relative slenderness was $\bar{\lambda}_{y}=0.23$ for buckling about the $y$-axis and $\bar{\lambda}_{z}=0.81$ about the $z$-axis. Both beam-columns ends were equipped with the end-plates of $30 \mathrm{~mm}$ (at the bottom) or $20 \mathrm{~mm}$ (at the top) thick ensuring the zero warping deformations of beam-column edges. The actual geometrical cross-sectional parameters were different compared to the tabular dimensions and were taken into account as the average values of measured geometrical parameters of all the tested members. 
Table 1: Basic and actual specimen cross-section dimensions.

\begin{tabular}{|c|c|c|}
\hline \multicolumn{3}{|c|}{ Basic cross-sectional dimensions IPE 120: } \\
\hline$H=$ & 120 & $\mathrm{~mm}$ \\
\hline$B=$ & 64 & $\mathrm{~mm}$ \\
\hline$t_{w}=$ & 4.4 & $\mathrm{~mm}$ \\
\hline$t_{f}=$ & 6.3 & $\mathrm{~mm}$ \\
\hline$r=$ & 7 & $\mathrm{~mm}$ \\
\hline \multicolumn{3}{|c|}{ Cross-sectional properties: } \\
\hline$A=$ & 1321.02 & $\mathrm{~mm}^{2}$ \\
\hline$I_{y}=$ & 3190221 & $\mathrm{~mm}^{4}$ \\
\hline$I_{z}=$ & 276682 & $\mathrm{~mm}^{4}$ \\
\hline$W_{\text {el. }}=$ & 53170.4 & $\mathrm{~mm}^{3}$ \\
\hline$W_{\text {el.z }}=$ & 8646.31 & $\mathrm{~mm}^{3}$ \\
\hline$W_{p l . y}=$ & 60700 & $\mathrm{~mm}^{3}$ \\
\hline$W_{p l . z}=$ & 13600 & $\mathrm{~mm}^{3}$ \\
\hline
\end{tabular}

\begin{tabular}{|c|c|c|}
\hline \multicolumn{3}{|c|}{ Actual cross-sectional dimensions IPE 120: } \\
\hline$H=$ & 120.4 & $\mathrm{~mm}$ \\
\hline$B=$ & 64.4 & $\mathrm{~mm}$ \\
\hline$t_{w}=$ & 4.8 & $\mathrm{~mm}$ \\
\hline$t_{f}=$ & 6.4 & $\mathrm{~mm}$ \\
\hline$r=$ & 7 & $\mathrm{~mm}$ \\
\hline \multicolumn{3}{|c|}{ Cross-sectional properties: } \\
\hline$A^{\prime}=$ & 1382.86 & $\mathrm{~mm}^{2}$ \\
\hline$I_{y}=$ & 3308073 & $\mathrm{~mm}^{4}$ \\
\hline$I_{z}=$ & 286621 & $\mathrm{~mm}^{4}$ \\
\hline$W_{\text {el. }}=$ & 54951.4 & $\mathrm{~mm}^{3}$ \\
\hline$W_{\text {el.z }}=$ & 8901.27 & $\mathrm{~mm}^{3}$ \\
\hline$W_{p l . y}=$ & 63117 & $\mathrm{~mm}^{3}$ \\
\hline$W_{p l . z}=$ & 14060 & $\mathrm{~mm}^{3}$ \\
\hline
\end{tabular}

The set of 4 types of members were tested, because of 4 combinations of loading. There were 3 specimens investigated for every combination of loading, thus 12 specimens in all were observed.

Members of type A were centrically loaded by axial force at the top side, thus without eccentricities in both main axis of cross-section. Consequently, members of type B were subjected to axial force with eccentricity at the direction of $y$-axis. Members of type $\mathrm{C}$ had eccentricity at the direction of $z$-axis and members of type $D$ had eccentricities in both axes.

Relative strains were measured by means of strain gauges 6/120 LY11. Lateral deflections were measured by potentiometer sensors TR 50 . Strains were recorded in places designated as h50 and $\mathrm{p} 50$, thus $50 \mathrm{~mm}$ from end plates and at places of $s$, which were at the distance of $500 \mathrm{~mm}$ from top end plate. Additionally, potentiometer sensors were located in points p40 and h40, thus $40 \mathrm{~mm}$ from end plates and in points of $s$, which were at the distance of $490 \mathrm{~mm}$ from top end plate. The pattern of measuring places is in Fig. 1. 
GAUGES

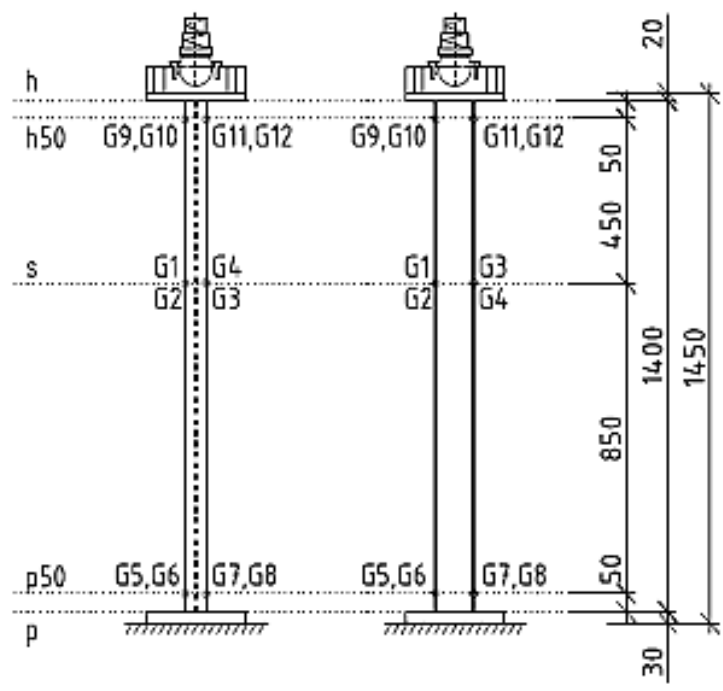

G OF CROSS-SECTION S

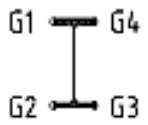

G OF CROSS-SECTION p50

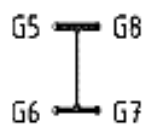

POTENTIOMETER SENSORS OF DEFORMATION

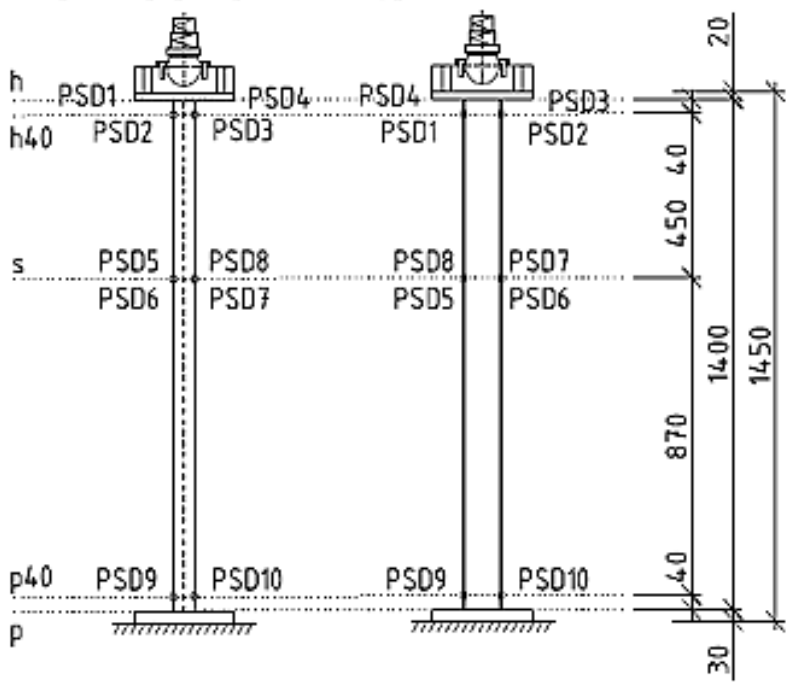

PSD OF CROSS-SECTION h 40

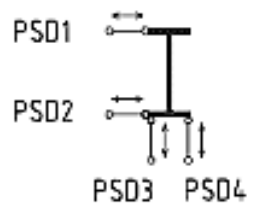

PSD OF CROSS-SECTION S

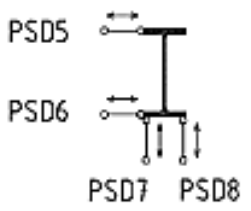

G OF CROSS-SECTION hSO

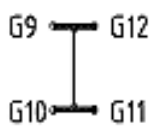

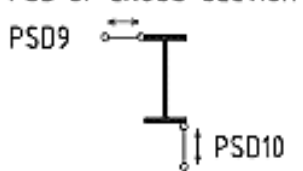

Fig. 1: Arrangement of measuring devices.

The initial eccentricities for verification according to standard [1] were measured before loading tests. These measured defects were assuming in following standard calculations because they should be involved in design approaches of European standards.

The loading was carried out in two stages [6]. At the first stage, the loading was provided only in elastic range with force increases of $20 \mathrm{kN}$. The functionality of the measuring devices and the loading system was checked at this part. Whereas at the second stage, the loading increases continued using deflection increases of $0.1 \mathrm{~mm}$, until the beam-column collapsed.

From the view of process and method of loading, it was necessary to evaluate the results obtained for every specimen in a way that the actual behaviour could be reviewed. Consequently, attention was mainly paid on elastoplastic state of the member acquired after reaching the strains $\varepsilon$ beyond $f_{y} / E$ limit.

For verification according to standards [1, 2], one specimen was selected from every set of members. In the case of member marked as A1, the first overrun of the yield strength was in the point of h50, at the force value of $312 \mathrm{kN}$. Subsequently, the second point in the line with exceeded yield strength was p50 at the force value of $323 \mathrm{kN}$. Finally, the plastic strains occurred in the place of $\mathrm{s}$ at the force value of $332 \mathrm{kN}$. The maximum force recorded within testing the member A1 was $346 \mathrm{kN}$. In the same way, in the process of loading the specimen B1, the first exceeding of yield strength was observed in the place of h50 at the force value of $77 \mathrm{kN}$, the second one was the cross-section in the point of p50 under the force of $110 \mathrm{kN}$. The maximum force recorded during testing the member B1 was $133 \mathrm{kN}$. In contrast, within testing the member $\mathrm{C} 1$, the first exceeding of yield strength was watched in the place of h50 under force of $172 \mathrm{kN}$, the second one was the cross-section in the point $s$ under the force of $200 \mathrm{kN}$ and finally in the cross-section of p50 at the force value of $221 \mathrm{kN}$. In the same way, the first exceeding of yield strength was observed in the point of h50 at the force value of $60 \mathrm{kN}$, the second one was the cross-section in the place of $\mathrm{s}$ under the force of $88 \mathrm{kN}$ and finally in the cross-section of p50 at the force value of $107 \mathrm{kN}$. Maximum recorded forces are shown in Table 2. 
Table 2: Maximum loading forces for specimens A1 - D3.

\begin{tabular}{|c|c|c|c|c|c|c|c|}
\hline Specimen & $\begin{array}{c}N_{R d, \max } \\
\mathrm{kN}]\end{array}$ & Specimen & $\begin{array}{c}N_{R d}, \max \\
{[\mathrm{kN}]}\end{array}$ & Specimen & $\begin{array}{c}N_{R d, \max } \\
{[\mathrm{kN}]}\end{array}$ & Specimen & $\begin{array}{c}N_{R d, \max } \\
{[\mathrm{kN}]}\end{array}$ \\
\hline $\mathrm{A} 1$ & 346 & $\mathrm{~B} 1$ & 133 & $\mathrm{C} 1$ & 221 & $\mathrm{D} 1$ & 107 \\
\hline $\mathrm{A} 2$ & 345 & $\mathrm{~B} 2$ & 149 & $\mathrm{C} 2$ & 220 & $\mathrm{D} 2$ & 114 \\
\hline $\mathrm{A} 3$ & 341 & $\mathrm{~B} 3$ & 148 & $\mathrm{C} 3$ & 211 & $\mathrm{D} 3$ & 112 \\
\hline
\end{tabular}

Another information related to investigation of specimen properties, imperfections and testing process were described in the doctoral thesis [3]. For all observed specimens, the plastic strains in the places h50 and p50 were occurred due to the effect of bending moments caused by the initial eccentricities. Therefore, forces which were recorded when plastic strains in the places of $s$ occurred were considered as the forces corresponding to the stability collapses. Measured eccentricities at the top side of specimens and recorded forces under stability collapses are presented in Table 3 . These forces were used for the final comparison to the forces at stability collapse calculated according to the standards $[1,2]$.

Table 3: Initial eccentricities and appropriate forces at stability collapse.

\begin{tabular}{|c|c|c|c|c|c|}
\hline Specimen & $e_{y}[\mathrm{~mm}]$ & $e_{z}[\mathrm{~mm}]$ & $\begin{array}{c}N_{E d . e x p} \\
{[\mathrm{kN}]}\end{array}$ & $\begin{array}{c}M_{y . E d} \\
\mathrm{kNm}]\end{array}$ & $\begin{array}{c}M_{z . E d} \\
\mathrm{kNm}]\end{array}$ \\
\hline $\mathrm{A} 1$ & 0 & 0 & 332 & 0 & 0.83 \\
\hline $\mathrm{B} 1$ & 31 & 0 & 115 & 0 & 2.76 \\
\hline $\mathrm{C} 1$ & 0 & 52 & 200 & 9.6 & 0.5 \\
\hline $\mathrm{D} 1$ & 31 & 55 & 88 & 4.84 & 2.73 \\
\hline
\end{tabular}

\section{Verification according to European standards}

\subsection{EN 1993-1-1 - Annex A}

This design method is aimed at proposing general, transparent, consistent and accurate interaction criteria. The real bending moment is substituted by equivalent sinusoidal bending moment by means of $C_{m}$ factor. The proposal has been derived as far as possible on theoretical aspects. In this method, each coefficient in formulae represents a single physical effect. It can be effective to identify the governing phenomenon and to propose an adequate design. As this method is derived to be as general as possible, it is covering a wide range of configurations, including unusual ones.

\subsection{EN 1993-1-1 - Annex B}

The objective of this method is more user-friendly proposal reducing the amount of design work. The aim is reached by means of providing design formulae in the basic format of the theoretical buckling equations using reduced number of coefficients for the calculation of the resistance against buckling. The actual distribution of bending moment is substituted by means of equivalent uniform moment for non-uniform moment diagrams.

The methods differentiate between members susceptible and not susceptible to torsional deformations. Members not susceptible to torsional deformations are hollow sections and open sections with appropriate torsional restraints. Accordingly, it provides two design equations for in-plane and out-of-plane buckling for two cases as follows:

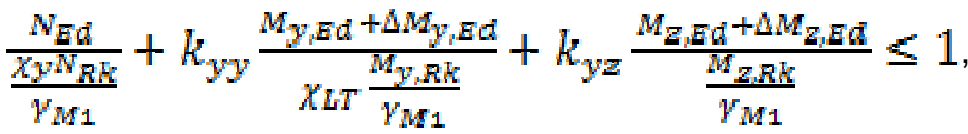

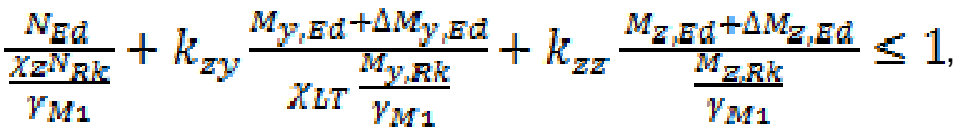


where:

$N_{E d}, M_{y, E d}$, and $M_{z, E d}$ are the design values of the compression force and the maximum bending moments about the $y-y$ and $z-z$ axis along the member,

$\Delta M_{y, E d}$ and $\Delta M_{z, E d}$ are the bending moments due to the shift of the centroid axis for class 4 of crosssections,

$\chi_{y}$ and $\chi_{z}$ are the reduction factors due to flexural buckling,

$\chi_{L T}$ is the reduction factor due to lateral torsional buckling,

$k_{y y}, k_{y z}, k_{z y}, k_{z z}$ are the interaction factors; they are relative to either method Annex A or Annex B of standard [1],

$N_{R k}, M y_{, R k}$, and $M_{z, R k}$ are the characteristic values of resistances to normal force and bending moments, $y-y$ and $z-z$ axis,

$\gamma_{m 1}$ is the partial factor for resistance of members to instability assessed by member checks.

The interaction factors are derived differently for class 1 or 2 cross-sections and for 3 or 4 ones respectively. Initially, it is necessary to classify the cross-section in accordance with standard [1]. Although, the classification may be done for compression and bending moment separately, however, for combination of compression and bending moment it should be accomplished too.

\subsection{EN 1999-1-1}

Classification of cross-sections for members with combined bending and axial forces is performed for the loading components separately. No classification is recommended for the combined state of stresses. The combined state of stresses is accounted for in the interaction formulae. The interaction formulas are the same for all the cross-section classes. The influence of yielding and local buckling is taken into account in the denominators and the exponents, which are functions of the member slenderness. Cross-section check is included in the check of flexural and lateral-torsional buckling, so there is not necessary to verify the cross-sectional resistance. Nevertheless, more crosssections along the member are needed to be checked.

Beam-column with open double-symmetric cross-section has to be verified for flexural buckling according to these two expressions:

eq. 1: $\left(\frac{N_{E d}}{\chi y \omega_{x} N_{R d}}\right)^{\xi_{y c}}+\frac{M_{y, E d}}{\omega_{0} M_{y, R d}} \leq 1$,

eq. 2: $\left(\frac{N_{E d}}{\chi_{z} \omega_{x} N_{R d}}\right)^{\eta_{C}}+\left(\frac{M_{Z, E d}}{\omega_{0} M_{z, R d}}\right)^{\xi_{z C}} \leq 1$,

where:

$\xi_{y c}=0.8$ or alternatively $\xi_{y c}=\xi_{0} \chi_{y}$, however $\xi_{y c} \geq 0.8$,

$\eta_{c}=0.8$ or alternatively $\eta_{c}=\eta_{0} \chi_{z}$, however, $\eta_{c} \geq 0.8$,

$\xi_{z c}=0.8$ or alternatively $\xi_{z c}=\xi_{0} \chi_{z}$, however, $\xi_{z c} \geq 0.8$,

$\eta_{0}, \xi_{0}, \gamma_{0}$ are defined in the section 6.2.9.1 of standard [2],

$\omega_{0}$ is the coefficient taking account the effect of cross welds, for cross-section with no cross welds $\omega_{0}=1$,

$N_{E d}, M_{y, E d}$, and $M_{z, E d}$ are the design values of the compression force and the bending moments about the $y-y$ and $z-z$ axis in the verified cross-section,

$N_{R d}, M_{y, R d}$, and $M_{z, R d}$ are the design values of resistances to normal force and bending moments about the $y-y$ and $z-z$ axis in the verified cross-section.

Beam-columns with open double-symmetric or mono-symmetric cross-sections have to be verified for lateral torsional buckling about the weak axis of cross-section according to following expression:

eq. 3: $\left(\frac{N_{E d}}{\chi_{Z} \omega_{x} N_{R d}}\right)^{\eta_{C}}+\left(\frac{M_{y, E d}}{\chi_{L T} \omega_{x L T} M_{y, R d}}\right)^{\gamma_{c}}+\left(\frac{M_{Z, E d}}{\omega_{0} M_{Z, R d}}\right)^{\xi_{z C}} \leq 1$, 


$$
\begin{aligned}
& \omega_{X}=\frac{\omega_{0}}{\chi+(1-\chi) \sin \frac{\pi x}{l_{C}}}, \\
& \omega_{x L T}=\frac{\omega_{0}}{\chi_{L T}+\left(1-\chi_{L T}\right) \sin \frac{\pi x}{l_{G}}},
\end{aligned}
$$

where:

$\omega_{x}$ and $\omega_{x L T}$ are the coefficients taking account the distribution of secondary bending moment along the member,

$x_{s}$ is the distance between support or point of inflection in the case of elastic flexural buckling and the point of verification,

$\omega_{0}$ is the coefficient taking account the effect of cross welds, for cross-section with no cross welds $\omega_{0}=1$

$\gamma_{c}=\gamma_{0}, \chi=\chi_{y}$, or $\chi_{z}$, reduction factors due to flexural buckling depending on the direction of buckling,

$l_{c}$ is the flexural buckling length,

$N_{E d}, M_{y, E d}$, and $M_{z, E d}$ are the design values of the compression force and the bending moments about the $y-y$ and $z-z$ axis in the verified cross-section,

$N_{R d}, M_{y, R d}$, and $M_{z, R d}$ are the design values of resistances to normal force and bending moments about the $y-y$ and $z-z$ axis in the verified cross-section.

Note: The labels eq. 1, eq. 2, and eq. 3 of expressions (3), (4), and (5) are simplified labels of these expressions for Tables 5, 6, and Fig. 2.

\subsection{Result comparison}

The maximum forces reached for the stability collapses determined by experimental analysis were compared to maximum forces obtained using formulas according to standards $[1,2]$. The yield strength was considered according to the material tests [3] with value of $300 \mathrm{MPa}$. Lateral torsional buckling was not considered in verification of specimens A1 and B1. For specimens C1 and D1, the lateral torsional buckling factor was determined according to section 6.3.2.4 in standard [1]. The flexural buckling length was considered by the value of $980 \mathrm{~mm}$ in all cases respecting the buckling mode of pinned-fixed beam-column. As was mentioned above, the cross-section was classified as the first class, therefore plastic section modulus was taken into account. The nominal values of Young's elasticity modulus $E=210 \mathrm{GPa}$ and shear modulus $G=81 \mathrm{GPa}$ were considered in all the calculations. Imperfection factors $\alpha_{l}=0.21$ for buckling in the $z$-axis direction and $\alpha_{1}=0.34$ for buckling in the $y$-axis direction were taken into account.

The final comparison of member resistances is presented in Table 4. From Table 4 it is clear that all the approaches are leading to similar accuracy when considering such end conditions and type of loading. However, they have different values of resistances in accordance with different combination of loading.

Table 4: Comparison of member resistances according to European standards and experimental analysis.

\begin{tabular}{|c|c|c|c|c|c|c|c|}
\hline \multirow{2}{*}{ Specimen } & $N_{\text {Ed.exp }}$ & $\begin{array}{c}\text { EN 1993-1-1 } \\
\text { Annex A }\end{array}$ & $\begin{array}{c}\text { EN 1993-1-1 } \\
\text { Annex B }\end{array}$ & EN 1999-1-1 & $\begin{array}{c}\text { EN 1993-1-1 } \\
\text { Annex A/N } / N_{\text {Edexp }}\end{array}$ & $\begin{array}{c}\text { EN 1993-1-1 } \\
\text { Annex B/ } N_{\text {Ed.exp }}\end{array}$ & $\begin{array}{c}\text { EN 1999-1-1 } \\
N_{\text {Ed.exp }}\end{array}$ \\
\cline { 2 - 8 } & {$[\mathrm{kN}]$} & {$[\mathrm{kN}]$} & {$[\mathrm{kN}]$} & {$[\mathrm{kN}]$} & {$[\%]$} & {$[\%]$} & {$[\%]$} \\
\hline $\mathrm{A} 1$ & 332 & 290 & 290 & 290 & 0.87 & 0.87 & 0.87 \\
\hline $\mathrm{B} 1$ & 115 & 126 & 124 & 107 & 1.10 & 1.08 & 0.93 \\
\hline $\mathrm{C} 1$ & 200 & 170 & 212 & 214 & 0.85 & 1.06 & 1.07 \\
\hline $\mathrm{D} 1$ & 88 & 94 & 88 & 93 & 1.07 & 1.00 & 1.06 \\
\hline
\end{tabular}

It can be seen from Table 4 that neither of the approaches is clearly conservative. In other words, such combination of loading can be found, where the design methods have generated higher member resistances as they were obtained by the experimental analysis.

There is an illustrated example of verification of the specimen D1 in Table 5 and Fig. 2 in accordance with standard [2]. The elastic cross-sectional resistance verification shows the impact of internal forces on the first plasticization of member at the cross-section of h50. 
Table 5: Resistance verification of beam-column D1 according to EN 1999-1-1.

\begin{tabular}{|c|c|c|c|c|c|c|c|c|c|c|c|c|}
\hline $\begin{array}{c}x_{s} \\
{[\mathrm{~mm}]}\end{array}$ & $\begin{array}{c}l_{c} \\
{[\mathrm{~mm}]}\end{array}$ & $\omega_{x y}$ & $\omega_{x z}$ & $\omega_{x L T}$ & $\begin{array}{c}M_{y \cdot E d} \\
{[\mathrm{kNm}]}\end{array}$ & $\begin{array}{c}M_{z . E d} \\
{[\mathrm{kNm}]}\end{array}$ & $\begin{array}{l}N_{E d} \\
{[\mathrm{kN}]}\end{array}$ & eq. 1 & eq. 2 & eq. 3 & $\begin{array}{l}\text { cross- } \\
\text { section } \\
\text { plastic }\end{array}$ & $\begin{array}{c}\text { cross-section } \\
\text { elastic }\end{array}$ \\
\hline 0 & \multirow{17}{*}{980} & 1.01 & 1.43 & 1.34 & 5.12 & 2.88 & 93 & 0.42 & 0.88 & 1.00 & 0.82 & 1.39 \\
\hline 100 & & 1.01 & 1.26 & 1.21 & 4.58 & 2.57 & 93 & 0.39 & 0.84 & 0.95 & 0.72 & 1.27 \\
\hline 200 & & 1.00 & 1.14 & 1.11 & 4.04 & 2.27 & 93 & 0.37 & 0.79 & 0.90 & 0.62 & 1.14 \\
\hline 300 & & 1.00 & 1.06 & 1.05 & 3.50 & 1.96 & 93 & 0.34 & 0.74 & 0.84 & 0.52 & 1.02 \\
\hline 400 & & 1.00 & 1.01 & 1.01 & 2.97 & 1.65 & 93 & 0.31 & 0.68 & 0.76 & 0.43 & 0.89 \\
\hline 490 & & 1.00 & 1.00 & 1.00 & 2.48 & 1.37 & 93 & 0.29 & 0.62 & 0.68 & 0.34 & 0.78 \\
\hline 500 & & 1.00 & 1.00 & 1.00 & 2.43 & 1.34 & 93 & 0.29 & 0.61 & 0.67 & 0.33 & 0.77 \\
\hline 600 & & 1.00 & 1.02 & 1.02 & 1.89 & 1.03 & 93 & 0.26 & 0.52 & 0.56 & 0.25 & 0.64 \\
\hline 700 & & 1.00 & 1.07 & 1.06 & 1.36 & 0.72 & 93 & 0.23 & 0.43 & 0.45 & 0.16 & 0.52 \\
\hline 800 & & 1.00 & 1.16 & 1.13 & 0.82 & 0.41 & 93 & 0.21 & 0.32 & 0.33 & 0.09 & 0.40 \\
\hline 900 & & 1.01 & 1.29 & 1.24 & 0.28 & 0.10 & 93 & 0.18 & 0.20 & 0.20 & 0.02 & 0.27 \\
\hline 980 & & 1.01 & 1.43 & 1.34 & -0.15 & -0.14 & 93 & 0.17 & 0.19 & 0.20 & 0.03 & 0.28 \\
\hline 1000 & & 1.01 & 1.39 & 1.31 & -0.26 & -0.21 & 93 & 0.18 & 0.22 & 0.22 & 0.04 & 0.30 \\
\hline 1100 & & 1.01 & 1.23 & 1.19 & -0.79 & -0.51 & 93 & 0.20 & 0.34 & 0.35 & 0.11 & 0.43 \\
\hline 1200 & & 1.00 & 1.12 & 1.10 & -1.33 & -0.82 & 93 & 0.23 & 0.45 & 0.47 & 0.19 & 0.55 \\
\hline 1300 & & 1.00 & 1.05 & 1.04 & -1.87 & -1.13 & 93 & 0.26 & 0.54 & 0.58 & 0.27 & 0.67 \\
\hline 1400 & & 1.00 & 1.01 & 1.01 & -2.40 & -1.44 & 93 & 0.29 & 0.63 & 0.69 & 0.36 & 0.80 \\
\hline
\end{tabular}

The verification of cross-sectional plastic resistance was accomplished by means of expression given in standard [1]:

$$
\left(\frac{M_{y, \bar{E} d}}{M_{N, y, R d}}\right)^{\alpha}+\left(\frac{M_{z, E d}}{M_{N, Z, R d}}\right)^{\beta} \leq 1
$$

where:

$M_{y, E d}$ and $M_{z, E d}$ are the design values of the bending moments about the $y-y$ and $z-z$ axis in the verified cross-section,

$M_{N, y, R d}$ and $M_{N, z, R d}$ are the design bending moment resistances taking into account the impact of axial force on bending moment resistances,

$\alpha, \beta 1.0$, or alternatively for I or H cross-sections $\alpha=2, \beta=5 n$, where $n=N_{E d} / N_{p l, R d}$, however $\beta \geq 1.0$.

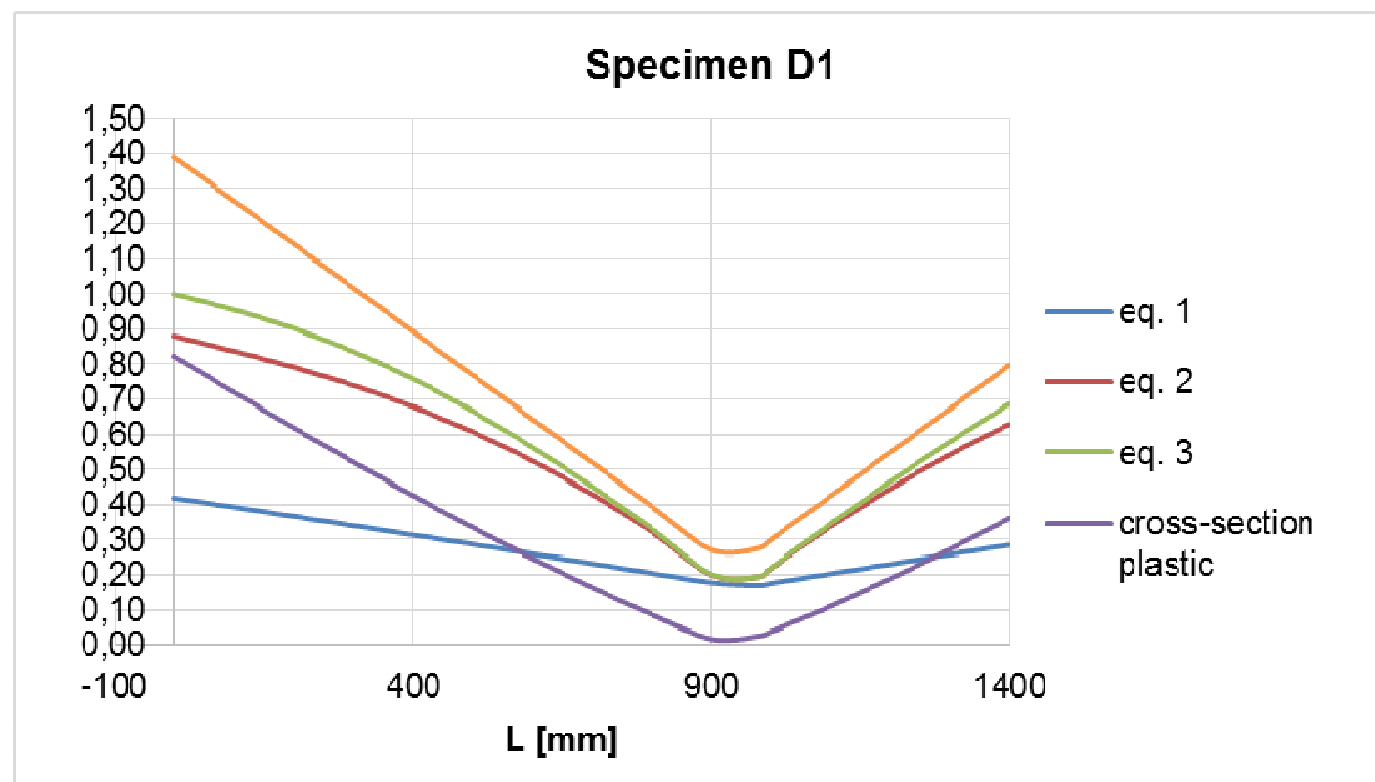

Fig. 2: Resistance verification of beam-column D1 according to EN 1999-1-1.

Subsequently, there is presented example of verification for the specimen $\mathrm{C} 1$ in Table 6 . In this case, the higher value of member resistance was calculated (by $7 \%$ ) and decisive expression was not 
the interaction formulae representing stability failure perpendicular to $z$-axis, which was observed in the experimental analysis too, but expression representing stability failure perpendicular to $y$-axis.

Table 6: Resistance verification of beam-column C1 according to EN 1999-1-1.

\begin{tabular}{|c|c|c|c|c|c|c|c|c|c|c|c|c|}
\hline $\begin{array}{c}x_{s} \\
{[\mathrm{~mm}]}\end{array}$ & $\begin{array}{c}l_{c} \\
{[\mathrm{~mm}]}\end{array}$ & $\omega_{x y}$ & $\omega_{x z}$ & $\omega_{x L T}$ & $\begin{array}{c}M_{y \cdot E d} \\
{[\mathrm{kNm}]}\end{array}$ & $\begin{array}{c}M_{z . E d} \\
{[\mathrm{kNm}]}\end{array}$ & $\begin{array}{l}N_{E d} \\
{[\mathrm{kN}]}\end{array}$ & eq. 1 & eq. 2 & eq. 3 & $\begin{array}{l}\text { cross- } \\
\text { section } \\
\text { plastic }\end{array}$ & $\begin{array}{l}\text { cross- } \\
\text { section } \\
\text { elastic } \\
\end{array}$ \\
\hline 0 & \multirow{17}{*}{980} & 1.01 & 1.43 & 1.34 & 11.13 & 0.00 & 214 & 1.00 & 0.41 & 0.81 & 0.84 & 1.13 \\
\hline 100 & & 1.01 & 1.26 & 1.21 & 9.96 & 0.00 & 214 & 0.95 & 0.49 & 0.89 & 0.67 & 1.07 \\
\hline 200 & & 1.00 & 1.14 & 1.11 & 8.79 & 0.00 & 214 & 0.89 & 0.56 & 0.93 & 0.52 & 1.00 \\
\hline 300 & & 1.00 & 1.06 & 1.05 & 7.62 & 0.00 & 214 & 0.83 & 0.62 & 0.95 & 0.39 & 0.94 \\
\hline 400 & & 1.00 & 1.01 & 1.01 & 6.45 & 0.00 & 214 & 0.78 & 0.66 & 0.92 & 0.28 & 0.87 \\
\hline 490 & & 1.00 & 1.00 & 1.00 & 5.40 & 0.00 & 214 & 0.72 & 0.67 & 0.87 & 0.20 & 0.81 \\
\hline 500 & & 1.00 & 1.00 & 1.00 & 5.29 & 0.00 & 214 & 0.72 & 0.67 & 0.87 & 0.19 & 0.81 \\
\hline 600 & & 1.00 & 1.02 & 1.02 & 4.12 & 0.00 & 214 & 0.66 & 0.65 & 0.78 & 0.11 & 0.74 \\
\hline 700 & & 1.00 & 1.07 & 1.06 & 2.95 & 0.00 & 214 & 0.60 & 0.61 & 0.68 & 0.06 & 0.68 \\
\hline 800 & & 1.00 & 1.16 & 1.13 & 1.78 & 0.00 & 214 & 0.54 & 0.55 & 0.58 & 0.02 & 0.61 \\
\hline 900 & & 1.01 & 1.29 & 1.24 & 0.61 & 0.00 & 214 & 0.48 & 0.48 & 0.48 & 0.00 & 0.55 \\
\hline 980 & & 1.01 & 1.43 & 1.34 & -0.32 & 0.00 & 214 & 0.47 & 0.41 & 0.42 & 0.00 & 0.53 \\
\hline 1000 & & 1.01 & 1.39 & 1.31 & -0.56 & 0.00 & 214 & 0.48 & 0.43 & 0.43 & 0.00 & 0.55 \\
\hline 1100 & & 1.01 & 1.23 & 1.19 & -1.72 & 0.00 & 214 & 0.54 & 0.51 & 0.53 & 0.02 & 0.61 \\
\hline 1200 & & 1.00 & 1.12 & 1.10 & -2.89 & 0.00 & 214 & 0.60 & 0.58 & 0.64 & 0.06 & 0.68 \\
\hline 1300 & & 1.00 & 1.05 & 1.04 & -4.06 & 0.00 & 214 & 0.66 & 0.63 & 0.75 & 0.11 & 0.74 \\
\hline 1400 & & 1.00 & 1.01 & 1.01 & -5.23 & 0.00 & 214 & 0.72 & 0.66 & 0.85 & 0.19 & 0.80 \\
\hline
\end{tabular}

Nevertheless, if the conservative values of exponents $\eta_{c}=0.8$ and $\xi_{z c}=0.8$ are considered in the verifications, the eq. 3 gives the decisive expression in case of specimen $\mathrm{C} 1$ representing the buckling resistance perpendicular to $z$-axis and considering the lateral torsional buckling. Regarding the values of exponents, for all combinations of loading, the final determined member resistances were on the safe side. The final values of verification for this case are illustrated in Table 7.

Table 7: Comparison of member resistance according to European standards and experimental analysis.

\begin{tabular}{|c|c|c|c|c|c|c|c|}
\hline \multirow{2}{*}{ Specimen } & $N_{\text {Ed.exp }}$ & $\begin{array}{c}\text { EN 1993-1-1 } \\
\text { Annex A }\end{array}$ & $\begin{array}{c}\text { EN 1993-1-1 } \\
\text { Annex B }\end{array}$ & EN 1999-1-1 & $\begin{array}{c}\text { EN 1993-1-1 } \\
\text { Annex A/N } N_{\text {Ed.exp }}\end{array}$ & $\begin{array}{c}\text { EN 1993-1-1 } \\
\text { Annex B/ } / N_{\text {Ed.exp }}\end{array}$ & $\begin{array}{c}\text { EN 1999-1-1 } \\
N_{\text {Ed.exp }}\end{array}$ \\
\cline { 2 - 8 }$[\mathrm{kN}]$ & {$[\mathrm{kN}]$} & {$[\mathrm{kN}]$} & {$[\mathrm{kN}]$} & {$[\%]$} & 0.87 & 0.87 \\
\hline $\mathrm{A} 1$ & 332 & 290 & 290 & 290 & 0.87 & 1.08 & 0.75 \\
\hline $\mathrm{B} 1$ & 115 & 126 & 124 & 86 & 1.10 & 1.06 & 1.00 \\
\hline $\mathrm{C} 1$ & 200 & 170 & 212 & 200 & 0.85 & 1.00 & 0.88 \\
\hline $\mathrm{D} 1$ & 88 & 94 & 88 & 77 & 1.07 & & {$[\%$} \\
\hline
\end{tabular}

\section{Conclusion}

When comparing member resistance of beam-column according to European standards to the results of experimental investigation of beam-columns with fixed-pinned end conditions subjected to eccentric axial force, it can be seen that observed approaches showed similar accuracy, even though values of their resistances were different according to various combinations of loading. The final verification includes safe values as well as the dangerous ones. However, when in the case of interaction formulas according to standard EN 1999-1-1 conservative values of exponents $\eta_{c}=0.8$ and $\xi_{z c}=0.8$ were applied, final values of verifications were not so accurate, but all were safe.

Although the calculation according to Annex A of the standard [1] is more complicated, the calculations are not generating more accurate results than the other ones.

\section{Acknowledgements}

The paper presents the results of the research project No. 1/0336/18 supported by the Slovak Grant Agency. 
This contribution is the result of the project implementation: „Supporting research and development center of excellence for civil engineering" (ITMS: 26220120031) supported by the Research \& Development Operational Programme funded by the ERDF.

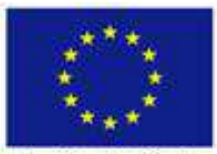

Európska únia

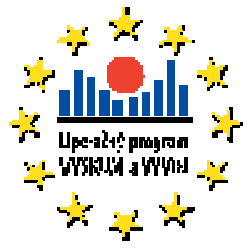

\section{References}

[1] EN 1993-1-1. Eurocode 3: Design of Steel Structures, Part 1 - 1: General Rules and Rules for Buildings, CEN Brussels, 2005.

[2] EN 1999-1-1, $2007+\mathrm{A} 1+\mathrm{A} 2$, Eurocode 9, Design of aluminium structures, Part $1-1$, General structural rules.

[3] JANÍK, P.: Resistance of beam-column subjected to transversal load and axial force. PhD- thesis, Department of Structures and Bridges, Faculty of Civil Engineering, University of Žilina, 2014.

[4] BREZINA, V.: Buckling resistance of metal members and beams. Prague, Czechoslovak Academy of Sciences, 1962 (in Czech).

[5] BOISSONNADE, N. - GREINER, R. - JASPART, JP. - LINDNER, J.: Rules for member stability in EN 1993-1-1, Background documentation and design guidelines, ECCS, 2006.

[6] PROTIVINSKÝ, J. - KREJSA, M.: An experimental verification of the applicability of steels S235 and DD11 for aseismic structural provisions. Mechanical Engineering, Materials Science, and Civil Engineering, $4^{\text {th }}$ international conference, Trans Tech Publications, 2017, pp. 2018 - 222. 